\title{
Optimization of dissolved Radon monitoring in groundwater to contribute to the evaluation of the seismic activity: an experience in central-southern Italy
}

\author{
M. D. Barberio ${ }^{1}$ (I) F. Gori ${ }^{1}$ M. Barbieri ${ }^{1}$ - A. Billi ${ }^{2} \cdot$ F. Casalati ${ }^{1}$ - S. Franchini ${ }^{1} \cdot$ L. Lorenzetti $^{1} \cdot$ M. Petitta $^{1}$
}

Received: 1 April 2020 / Accepted: 6 July 2020 / Published online: 17 July 2020

(C) The Author(s) 2020 OPEN

\begin{abstract}
Anomalies in Radon $\left({ }^{222} \mathrm{Rn}\right)$ concentrations prior to earthquakes have been widely documented in seismogenic areas worldwide, but questions about their predictability remain largely unanswered. Even if it is not universally accepted, the analysis of the high-resolution time series of $\mathrm{Rn}\left({ }^{222} \mathrm{Rn}\right)$ concentrations in groundwater, air and soil has been proposed as a suitable method to identify seismic precursors. This study, which is aimed at identifying potential gas-geochemical precursors to nearby earthquakes, analyses groundwater Rn concentrations, which were continuously measured between April 2017 and December 2019. We conducted a detailed time series analysis of dissolved $\mathrm{Rn}$ in two springs emerging along two active fault zones in the inner sector of the central-southern Apennines (i.e. the Matese and Morrone fault zones) in Italy. We used a simple statistical method to identify seismic precursor anomalies in Rn concentrations. Anomalies are commonly assumed as values exceeding $\pm 2 \sigma$. Furthermore, we calculated the strain radius (for which a gas-geochemical precursor was expected) and the epicentral distance (from both our monitoring stations) of each seismic event of $M_{\mathrm{w}} \geq 3.5$ that occurred in the monitoring area. Results from our ongoing research are promising and show significant correlations between seismic signals and Rn concentrations. However, longer time series data that include more energetic earthquakes are needed to shed light on the behaviour of this gas in relation to crustal deformation processes.
\end{abstract}

Keywords Radon · Earthquakes · Precursors · Geochemistry · Groundwater · Springs

\section{Introduction}

Studies about earthquake-induced natural processes have always fascinated scientists all over the world. To date, scientific research has produced several results [1-4], which in most cases are represented by the detection of geophysical or geochemical anomalies in acquired long time series data. These anomalies have been highlighted in different geoscience disciplines and concern variations in: foreshock sequences [5], ratios of seismic wave velocities $\mathrm{Vp} / \mathrm{Vs}$ [6], electromagnetic fields [7], surface deformations [8], groundwater flow and chemistry [9-14] and gas emissions [15-18]. In particular, Radon $\left({ }^{222} \mathrm{Rn}\right)$ has been widely investigated over the last few decades as a potential seismic precursor candidate [10, 19-21].

However, despite these studies, there are still several significant gaps in adopting $\mathrm{Rn}$ as an earthquake precursor. According to a previous study [22], there are many reasons for poor understanding of possible precursor activity, such as inadequate statistical evidence, the lack of long-term measurements and the difficulty in distinguishing between seasonal variations and anomalies at the same magnitude. Acquiring a solid understanding of the chemical and physical processes occurring in the Earth's upper crust requires a substantial number of measurements. ${ }^{222} \mathrm{Rn}$ is an endogenous natural noble gas with

M. D. Barberio, marinodomenico.barberio@uniroma1.it | ${ }^{1}$ Earth Sciences Department, Sapienza University of Rome, P.le Aldo Moro 5, 00185 Rome, Italy. ${ }^{2}$ Consiglio Nazionale delle Ricerche, IGAG, Rome, Italy. 
a radioactive half-life of 3.82 days produced by a-decay from Radium $\left({ }^{226} \mathrm{Ra}\right)$. It is highly soluble in water, and the behaviour of $\mathrm{Rn}$ in groundwater is influenced by the geological nature of the substratum. The concentration of $\mathrm{Rn}$ in soil depends strongly on chemical, physical and geological factors, such as grain size, porosity and permeability along with seasonal variations, including temperature and atmospheric pressure $[23,24]$. The migration of $\mathrm{Rn}$ is driven by rock permeability, which increases with the presence of fractures, structural discontinuities and karst cavities $[25,26]$. Both mechanisms of Rn transport (diffusion and advection) depend on rock porosity and permeability, which at the same time vary as a function of the stress field [27]. Due to changes in crustal stress/strain and variations in pore pressure that occur before earthquakes, anomalies in $\mathrm{Rn}$ concentrations have been traced and analysed in seismogenic areas worldwide $[28,29]$. This evidence is associated with changes in water-rock interactions, which is commonly explained as the strong ability of gas migration promoted by the creation of highly permeable zones, such as microcracks and fractures.

Since 2014, with the aim of establishing new hydrogeological, hydrogeochemical, and gas-geochemical monitoring sites, a few pilot sites for the research of seismic precursors have been installed in the central-southern Apennines (Italy), where they have been continuously monitored and updated [12-14, 30,31]. This study presents the results obtained from the investigation of $\mathrm{Rn}$ gas concentrations in groundwater that were continuously measured in two springs fed by regional carbonate aquifers in Italy. The aim of this paper is to evaluate whether the high-frequency monitoring of Rn dissolved in groundwater can be correlated with regional seismic activity, hence contributing to the identification of potential seismic precursors. Furthermore, the creation and development of regional monitoring networks comprising a large number of sensors for the measurement of dissolved Rn will allow a better understanding of the behaviour of this gas in relation to seismic activity and hydrogeological factors.

\section{Geological and hydrogeological settings}

The central-southern Apennine chain is an east-verging fold-thrust belt related to the west-dipping subduction of the Apulian lithosphere [32], which was developed during the Neogene and Quaternary periods. This mountain chain is characterized by NE-verging thrust faults, which dissected the tectonic edifice into several thick tectonic sheets. The post-orogenic crustal extensional regime has progressively cut across these thrust sheets from the Messinian-Pliocene onwards [33, 34] (Fig. 1). In particular, systems of NW-striking normal faults have created halfgraben intramountain basins mostly filled by PlioceneQuaternary continental deposits [35]. At present, the extensional regime is strongly seismogenic along the axis of the central Apennines, while the compressional regime is active along the eastern margin of the Apennines and beneath the western Adriatic Sea [36-38] (Fig. 1).

The Apennine belt is characterized by huge fractured aquifers hosted by Meso-Cenozoic carbonate sequences. Due to the fold-thrust belt structure, the groundwater flowpath of the fractured aquifers is controlled at their base by the geometry of tectonic and stratigraphic contacts with low-permeability layers (aquicludes), such as pre- and syn-orogenic basinal and flysch clayey series [39]. The aquifer systems are characterized by high transmissivity, which is mostly due to fractures and karst cavities. Significant flow through springs is usually both stable and huge.

In this work, we performed continuous monitoring of $\mathrm{Rn}$ in two springs: the Giardino spring (SG) and the Rio Freddo spring (SRF) located at Lat. $42.162819^{\circ}$ and Long. $13.841160^{\circ}$ and at Lat. $41.472902^{\circ}$ and Long. $14.496860^{\circ}$, respectively; the springs are fed by two regional carbonate aquifers: Mt. Morrone and the Matese Mts (Fig. 2A). In the northern sector, the Mt. Morrone aquifer is bounded by the thrust zone between the Gran Sasso carbonate unit and the Mt. Morrone carbonate unit. In the eastern sector, it is bounded by the thrust zone between the Mt. Morrone unit and the Laga siliciclastic unit, while in the western sector, it is bounded by the Mt. Morrone active extensional fault [40]. The SG (Fig. 2A) is a main discharge outlet of the Mt. Morrone aquifer and is characterized by steady flow and chemical regimes with a high discharge rate of approximately $1 \mathrm{~m}^{3} / \mathrm{s}[12,31]$. Its waters are predominantly tapped by the local drinking water company (ACA Pescara). This spring is located at the north-western boundary of the aquifer at the intersection with the Mt. Morrone normal fault (striking NW-SE by approximately $25 \mathrm{~km}$ and dipping towards the SW: Fig. 2A). This fault triggered pre-historical earthquakes up to $M_{\mathrm{w}} 6.5$ or stronger. The current rate of extension in this area assessed through GPS measurements is 3-4 mm/a [8].

The wide karst area of the Matese Mts aquifer crops out in the median sector of the Apennine chain and presents high slopes and elevations up to $2050 \mathrm{~m}$ [41]. Carbonate sequences are represented by limestone and limestone-dolostone (late Triassic-Miocene) series with a thickness ranging between 2500 and $3000 \mathrm{~m}$. Along the northern and eastern sectors, the Matese massif (hanging wall) is tectonically bounded by a thrust fault onto younger low-permeability argillaceous complexes and flysch sequences (footwall). Along the southern and 


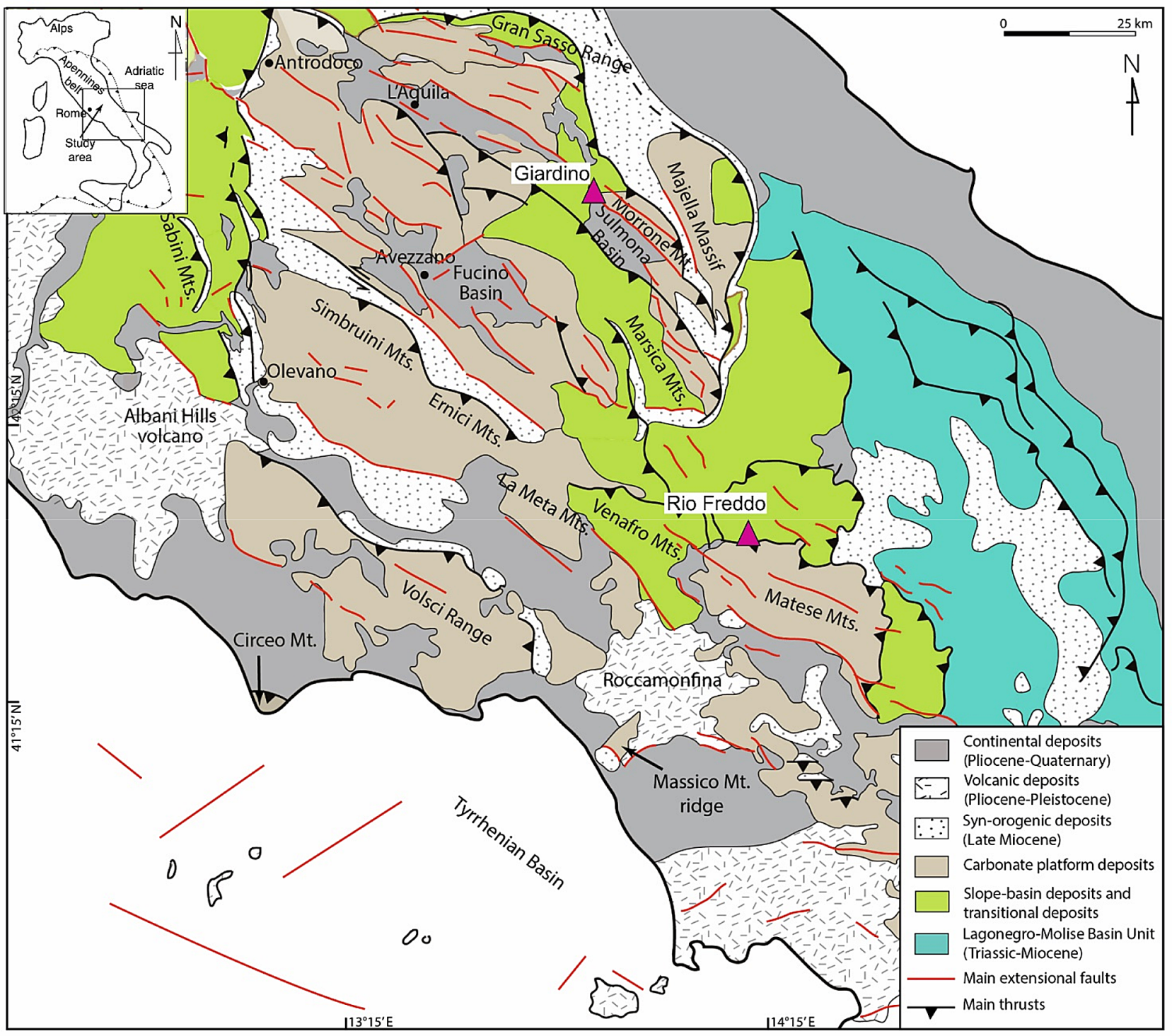

Fig. 1 Regional geological map of central-southern Apennines, Italy. Modified from [34]

western sectors, the massif is bounded by normal faults, and it is covered by recent Quaternary deposits of the Volturno river plain. Three main groups of springs are fed along the northern side of the massif near the village of Bojano [42]. These springs are fed by the karst system of the north-central sector of the Matese massif and have a total mean discharge of about $2.8 \mathrm{~m}^{3} / \mathrm{s}$. Most of them are tapped by A.S.R. Molise Acque for drinking purposes. The SRF (Fig. 2A) is located east of the village of Bojano along debris deposits that cover the fault between the limestone and flysch sequences [43]. The Matese area is a region characterized by high seismicity with a NE-SW extension rate of $2.0 \pm 0.2 \mathrm{~mm} / \mathrm{a}$ estimated via GPS data [44].

\section{Materials and methods}

To investigate the relationship between Rn gas in groundwater and seismic activity, Rn concentrations were continuously measured between April 2017 and December 2019 in the SG and between June 2018 and December 2019 in the SRF. To strip gas from the water, the study used an AlphaGUARD probe (Model PQ2000PRO: see Fig. 2B, C) with high-capacity storage equipped with a RAM 7 module. The gas was subsequently sent to the detector for measurements through a low-flow pump. Moreover, in addition to $\mathrm{Rn}$ water concentrations, the device simultaneously recorded ambient temperature, relative humidity, and atmospheric pressure thanks to additional sensors. The AlphaGUARD detector consists 


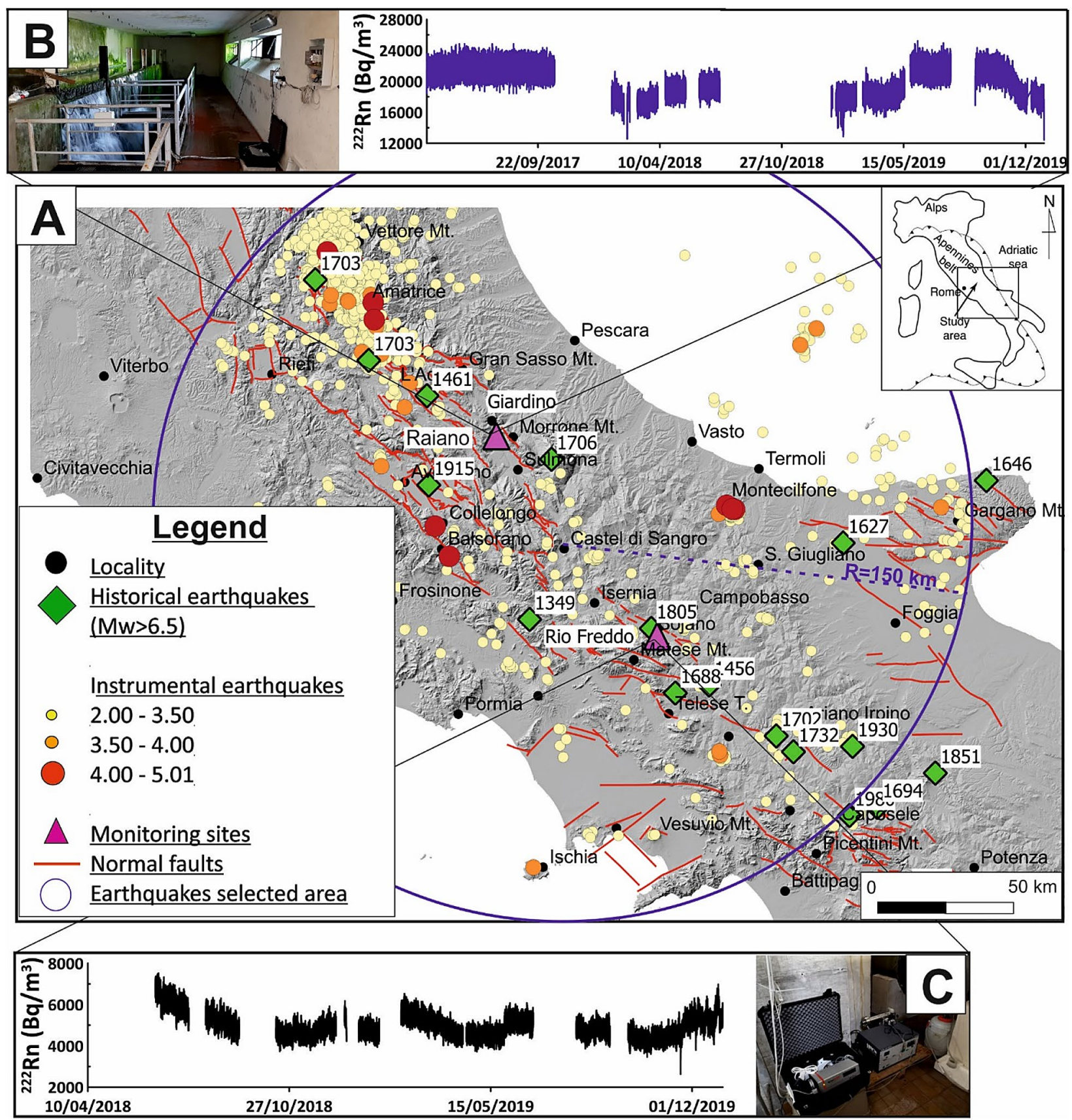

Fig. 2 A Map of central-southern Apennines, Italy. Location of springs is displayed with cyan triangular symbols. Earthquakes (1 April 2017-31 December 2019) occurred in the study area are displayed with circles of different size and colour depending of their magnitude. Historical earthquakes $\left(M_{w} \geq 6.5\right)$ are shown with green rhombuses. Seismic data are from the INGV database (available

of a pulse ionization chamber associated with an alpha spectrometer that recognizes the specific pulses caused by $\mathrm{Rn}$. The probe guarantees a fast and precise response to different concentrations and maintenance-free operation, owing to its long-term stable calibration (sensitivity $1 \mathrm{CPM}$ at $20 \mathrm{~Bq} / \mathrm{m}^{3}$ : error of $3 \%$ ) and is suitable for the online at http://terremoti.ingv.it/). B AlphaGUARD probe (left) and time series (1 April 2017-31 December 2019) of Rn concentrations (right) at SG. C AlphaGUARD probe (right) and time series (1 June 2018-31 December 2019) of Rn concentrations (left) detected at SRF

continuous measurement of Rn concentrations between $2-2,000,000 \mathrm{~Bq} / \mathrm{m}^{3}$. The automatic data-sampling frequency was set to every $10 \mathrm{~min}$. The two instruments were installed in the surplus flow at the exit of the two collected springs. To identify potential seismic precursors, these springs were also sampled monthly together with

\section{SN Applied Sciences}


other selected springs $[12,14]$ to determine their chemical-physical parameters, major ions, trace elements and stable water isotopes.

\section{Results}

The Rn concentrations in the groundwater were measured between April 2017 and December 2019 in the SG (Fig. 2B) and between June 2018 and December 2019 in the SRF (Fig. 2C). The waters of the SG and SRF are mainly enriched in bicarbonate and calcium ions ( $\mathrm{Ca}-\mathrm{HCO}_{3}$ facies) due to carbonate dissolution. In terms of chemical-physical parameters (e.g. pH, temperature and electrical conductivity), both springs are characterized by a slightly basic $\mathrm{pH}$ of 7.85 , temperatures ranging from 7.8 to $11.9^{\circ} \mathrm{C}$, and limited mineralization defined by electrical conductivity values of 315 and $263 \mu \mathrm{s} / \mathrm{cm}$ for the SG and the SRF, respectively. Both Rn time series included missing data that corresponded to periods of probe maintenance or periods of low water flow when the probe emerged, thus measuring atmospheric Rn concentration. Acquisition disturbances were also caused during monthly data download operations. The Rn concentration maximum values were 25,216 and $7520 \mathrm{~Bq} / \mathrm{m}^{3}$, while the minimum ones were 12,416 and $2624 \mathrm{~Bq} / \mathrm{m}^{3}$ for the SG and SRF, respectively. In the time series shown in Fig. 2B, C, the dissolved Rn concentrations appear to be variable around the average values of $20,068.83$ and $5038.3 \mathrm{~Bq} / \mathrm{m}^{3}$, respectively. However, it is possible to observe seasonal variations or rapid changes in $\mathrm{Rn}$ content commonly linked to the hydrogeological and hydrological cycles [22].
Figure $2 \mathrm{~A}$ shows the background seismicity of the study area (available online: http://terremoti.ingv.it/), which was recorded in the same period of the gas-geochemical monitoring. Earthquakes that occurred in an area with a radius of $150 \mathrm{~km}$ centred on Castel di Sangro (Lat. $41.783991^{\circ}$, Long. $14.108032^{\circ}$ ) were selected. This locality is the midpoint between the two monitoring stations (i.e. the $S G$ and SRF in Fig. 2A). The $M_{w} 5.1$ Montecilfone earthquake, which occurred in Molise on August 16, 2018, was the main seismic event during the monitoring period (2017-2019).

\section{Time series processing and interpretation}

This study conducted some simple data processing to identify potential anomalies in Rn concentrations related to seismic activity. In particular, some simple elaborations were adopted, which were similar to those that allowed other researchers to identify significant evidence of correlations between gas anomalies and seismic activity in tectonically active areas $[2,21,45,46]$. The frequency of $R n$ activity for both springs is described by the typical Gaussian distribution (Fig. 3). Hence, the recorded fluctuations (whether temporal, diurnal or seasonal) are within the range included in $M \pm 2 \sigma$, where $M$ and $\sigma$ are the mean and standard deviations of the time series, respectively, [47]. Instead, anomalies in Rn concentrations are defined as significant deviations from the mean value; specifically, it is commonly assumed that signals related to earthquakes fall outside the so-called 2- $\sigma$ confidence interval [48].

Based on these studies, the mean values and the standard deviations of Rn activity, which are useful for

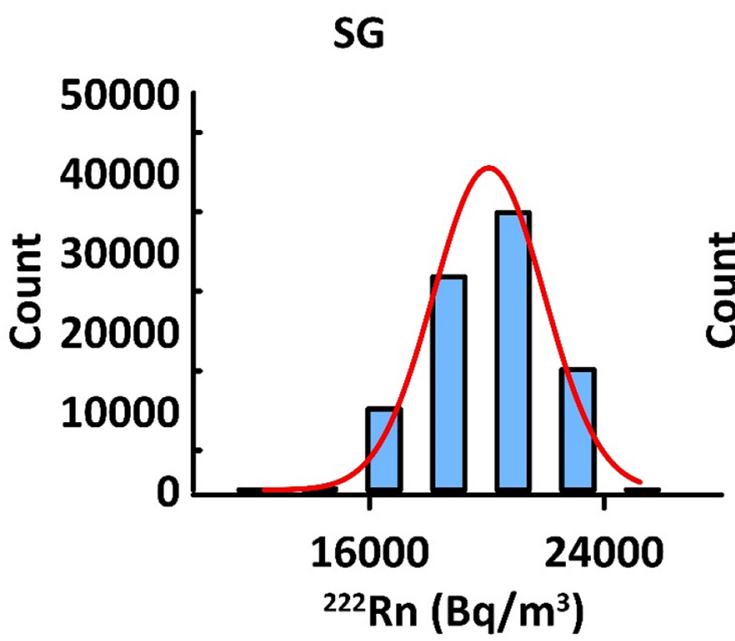

Fig. 3 On the $X$-axis, the Rn activity is shown $\left(\mathrm{Bq} / \mathrm{m}^{3}\right)$; on the $Y$-axis the count is displayed. The frequency of Rn activity for both springs (SG on the left and SRF on the right) is described by the typical

\section{SRF}

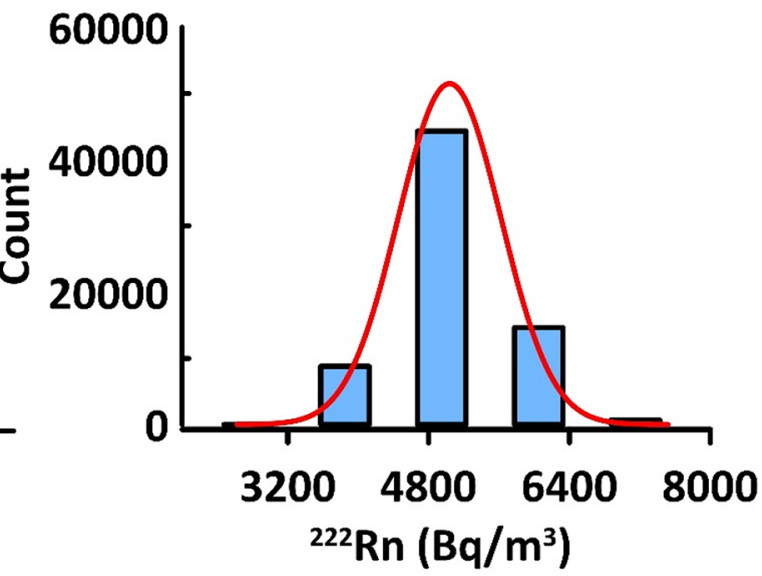

Gaussian distribution, represented as the symmetric "bell curve" shape with a red line 
the detection of outliers, have been calculated for the SG (SG0, Fig. 4) and for the SRF (Fig. 5). The acquired time series are shown in Figs. 4 and 5 with three-hour moving averages, which were adopted to eliminate data noise. The mean values and the $\pm \sigma$ and $\pm 2 \sigma$ thresholds are also displayed in graphs by solid and dashed lines, respectively. These graphs also show seismic events of $M_{\mathrm{w}} \geq 3.5$ (taken from the previously described database).
In Fig. 4, SG0 represents the entire SG time series recorded between April 2017 and December 2019. Since this series is uneven, the sequence has been separated into four sections (SG1-SG4 in Fig. 4) to improve the accuracy of the processing. No intervals exceeding the $\pm 2 \sigma$ thresholds in relation to the seismicity of the study area are observed. However, decomposing the SRF time series is not necessary, as the data show a relatively limited variation from the mean value of about $5000 \mathrm{~Bq} /$
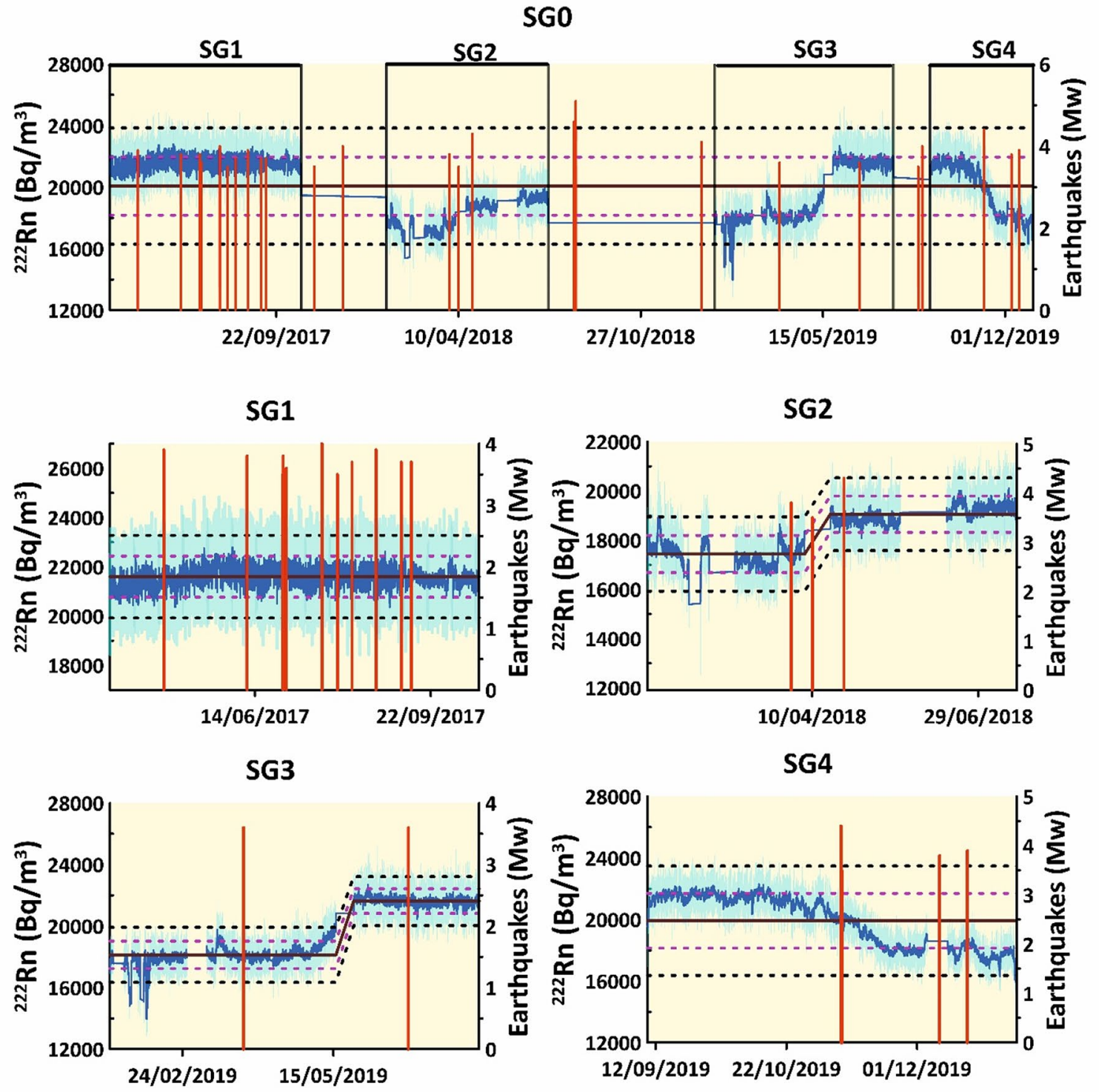

\section{Rn Giardino \\ Rn-Running - Mean value $\cdots \pm 2$ Sigma $\cdots \pm$ Sigma - Earthquakes average $3 \mathrm{~h}$}

Fig. 4 Time series (1 April 2017-31 December 2019) of Rn concentrations recorded at SG (SG0). SG1, SG2, SG3, and SG4 are the four segments into which the sequence was divided. Rn activity is displayed with cyan lines, while its moving averages of $3 \mathrm{~h}$ are shown with blue lines. Mean values and the $\pm \sigma$ and $\pm 2 \sigma$ thresholds are displayed with solid lines and with dashed ones, respectively. Seismic events with $M_{\mathrm{w}} \geq 3.5$ (from the INGV database, available online at http://terremoti.ingv.it/) are shown with red bars 


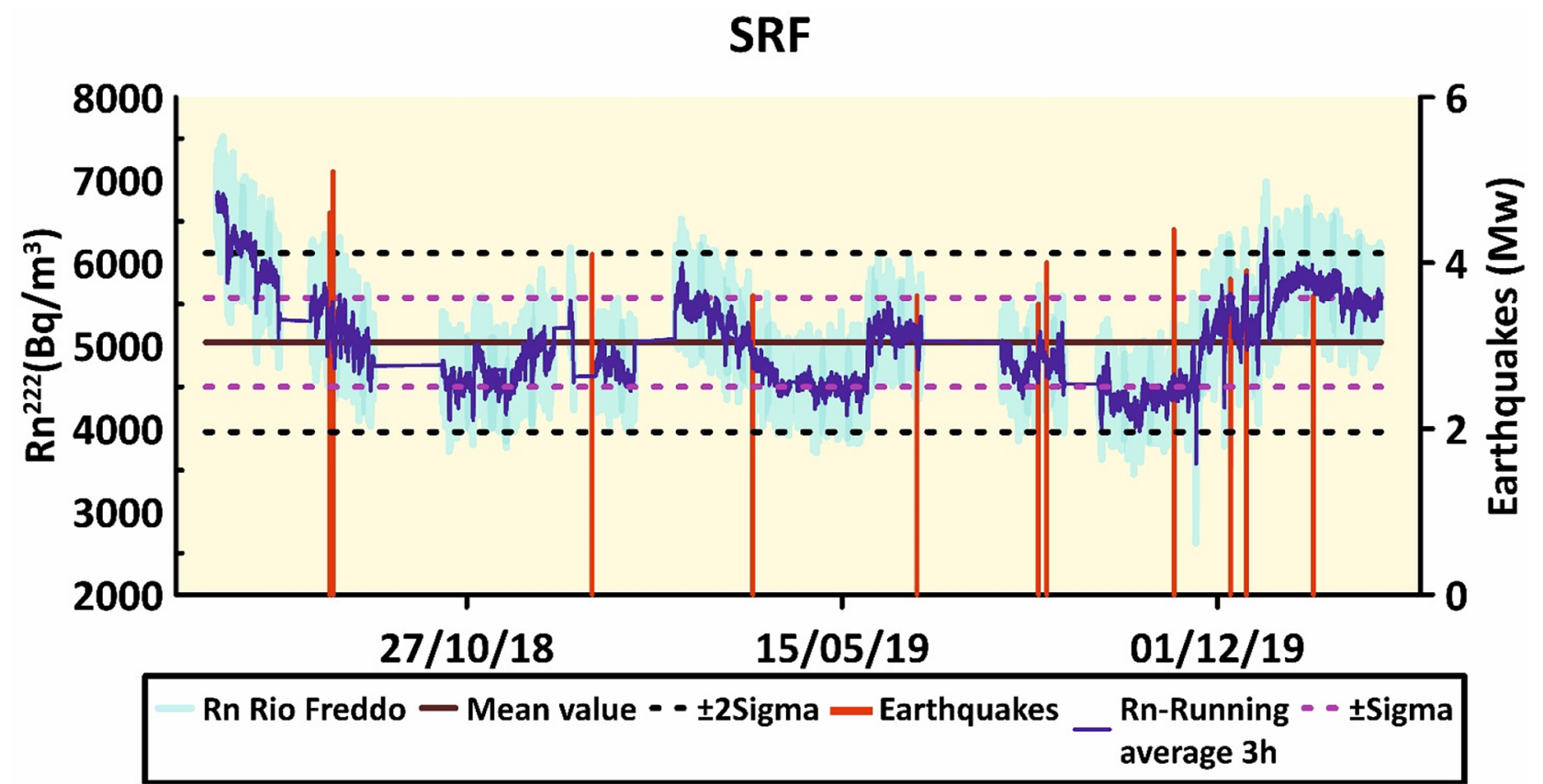

Fig. 5 Time series (1 June 2018-31 December 2019) of Rn concentrations recorded at RFS. Rn activity is displayed with cyan line, while its moving averages of $3 \mathrm{~h}$ are shown with blue line. Mean value and the $\pm \sigma$ and $\pm 2 \sigma$ thresholds are displayed with solid line

$\mathrm{m}^{3}$ (Fig. 5). Additionally, in this case, as for the SG, there are no intervals exceeding the $\pm 2 \sigma$ thresholds in relation to seismic activity. The values exceeding $\pm 2 \sigma$ are due to different conditions: (1) at the SG, they are related to sensor emersions above the water surface (Fig. 4), while (2) at the SRF, they are represented by the initial values of the time series that are presumably attributable to another condition (before the start of monitoring), whose course is not known (Fig. 5).

Additionally, a different data processing procedure was considered. According to Dobrovolsky et al. [49], two parameters must be treated together to calculate the strain radius ( $R$ in $\mathrm{km}$ ) of the effective precursory manifestation zone: the magnitude of the earthquake $\left(M_{\mathrm{w}}\right)$ and the distance between the epicentre and the measuring site $(D$ in $\mathrm{km})$. In this way, these authors defined a relationship to identify the interactions between gasgeochemical and seismic signals using the following empirical equation:

$R=10^{0.43 \times M}$

where $R$ is the strain radius of the precursory manifestation zone and $M$ is the moment magnitude $\left(M_{\mathrm{w}}\right)$.

The conceptual basis of Eq. (1) is that an approximately circular region around the epicentre of the earthquake should undergo elastic crustal deformation prior and with dashed ones, respectively. Seismic events with $M_{w} \geq 3.5$ (from the INGV database, available online at http://terremoti.ingv. it/) are shown with red bars

to earthquakes [50]. Therefore, precursory signals were expected for events where $R \geq D$. Considering two earthquakes of the same magnitude, a closer seismic event affects the Rn activity in the monitoring site more significantly than a distant one.

Equation (1) was applied to $M_{w} \geq 3.5$ earthquakes that occurred at the two study sites (between April 2017 and December 2019). Epicentral distances from the two sites were also determined (Fig. 6). This processing allowed the identification of five seismic events for the $\mathrm{SG}$ and six seismic events for the SRF, in which a possible Rn response was expected in terms of geochemical precursor signals.

The response could not be verified for three of the five seismic events identified at the SG due to the lack of Rn data, while no interaction was observed for the four Montecilfone seismic events at the SRF. The non-interaction between the gas content and the Montecilfone earthquakes has a geodynamic explanation; these seismic events occurred in a different plate (i.e. in the Adria plate subducting towards the SW beneath the Apennines) from the Apennine belt where the monitoring sites are located [51]. Therefore, it is not surprising that the Montecilfone seismic sequence did not cause anomalies in the inner sector of the Apennines.

Overall, three seismic events produced expected Rn activity responses as presented in Fig. 7 . Specifically, the $M_{\mathrm{w}} 3.8$ L'Aquila earthquake, which occurred on March 31st, 

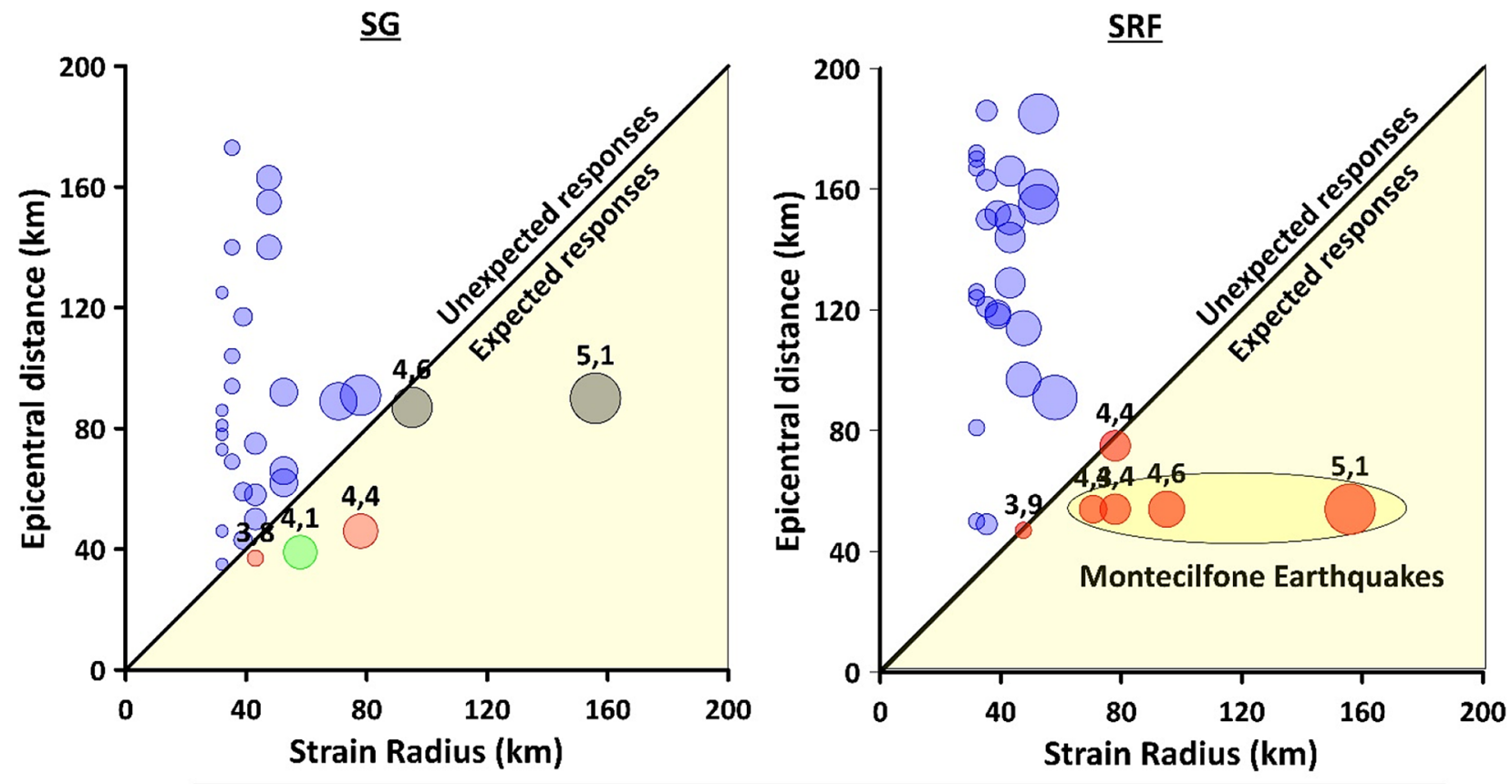

- Unexpected interaction $\odot$ No Data $\odot$ Probe in air $\odot$ Expected interaction

Fig. 6 Seismic events with $M_{\mathrm{w}} \geq 3.5$ in the $R-D$ plane, where $R$ is the strain radius of the precursory manifestation zone, and $D$ is the epicentral distance $(\mathrm{km})$ from the two springs $[49,50]$. Earthquakes, for which an interaction between gas-geochemical and seismic signals was supposed, fall into the "expected responses" area (the

2018, was detected at the SG; the $M_{\mathrm{w}} 4.4$ Balsorano earthquake, which occurred on 7 November 2019, produced responses at both springs; and the $M_{\mathrm{w}}$ 3.9 San Leucio del Sannio earthquake, which occurred on 16 December 2019, produced a response at the SRF. These two latter events present comparable $R$ and $D$ values at the SRF. For this reason, they fall on the straight line (Fig. 6, SRF) that separates the expected interaction area $(R \geq D)$ from the unexpected interaction area $(R<D)$. Specifically, an increase in Rn concentration (which lasted for about $12 \mathrm{~h}$ ) of $\approx 1200 \mathrm{~Bq} / \mathrm{m}^{3}$ (7\% with respect to the average value) and another one of $\approx 1500 \mathrm{~Bq} / \mathrm{m}^{3}$ ( $8 \%$ with respect to the average value) were observed at the SG seven and 11 days before the L'Aquila and the Balsorano earthquakes, respectively (the black arrow in the SG, Fig. 7A, B). For the latter earthquake, a decrease of approximately $2000 \mathrm{~Bq} / \mathrm{m}^{3}$ (after the peak) was also observed. Another increase in Rn concentration of $\approx 500 \mathrm{~Bq} / \mathrm{m}^{3}$ (10\% with respect to the average value, which lasted about six hours) was recorded at the SRF about 17 days before the Balsorano earthquake (the black arrow on the left in the SRF, Fig. 7C). A different $\mathrm{Rn}$ behaviour was identified at the SRF before the San Leucio del Sannio earthquake. The preparation phase of this seismic event is illustrated by a clear increasing trend label indicates the $M_{\mathrm{w}}$ earthquake). Only red circles are taken into consideration due to lack of Rn data, sensor emersions, and unexpected interactions that are displayed with black, green and blue circles, respectively

during the month of November of $\approx 1000 \mathrm{~Bq} / \mathrm{m}^{3}(20 \%$ with respect to the average value: the black arrow at the SRF on the right, Fig. 7). In all the observed cases, it can be inferred that changes in the strain field before seismic activity may have affected gas and fluid migration, causing an increase in Rn content ranging from 7 to $20 \%$ with respect to (background) pre-anomaly values. Therefore, the recorded pre-seismic signals could be explained as the result of dilation and/or contraction of fracture systems that led to changes in the gas flow behaviour; however, it is believed that a more accurate analysis of time lags between the Rn signals and the occurrence of earthquakes is necessary, as the identified interactions are too limited in number to clarify this aspect. Additionally, processes of dilation and/or contraction are expected to drive some changes in the chemical content of groundwater, whose intensity would be inversely correlated with the groundwater resource volume in the corresponding aquifers due to different dilution rates. Furthermore, some transient and evident perturbations in Rn concentrations before the San Leucio del Sannio earthquake were detected, but these were attributed to the users' field interventions. The sampling frequency of 10 min allowed the acquisition of accurate data through which it was possible to measure 

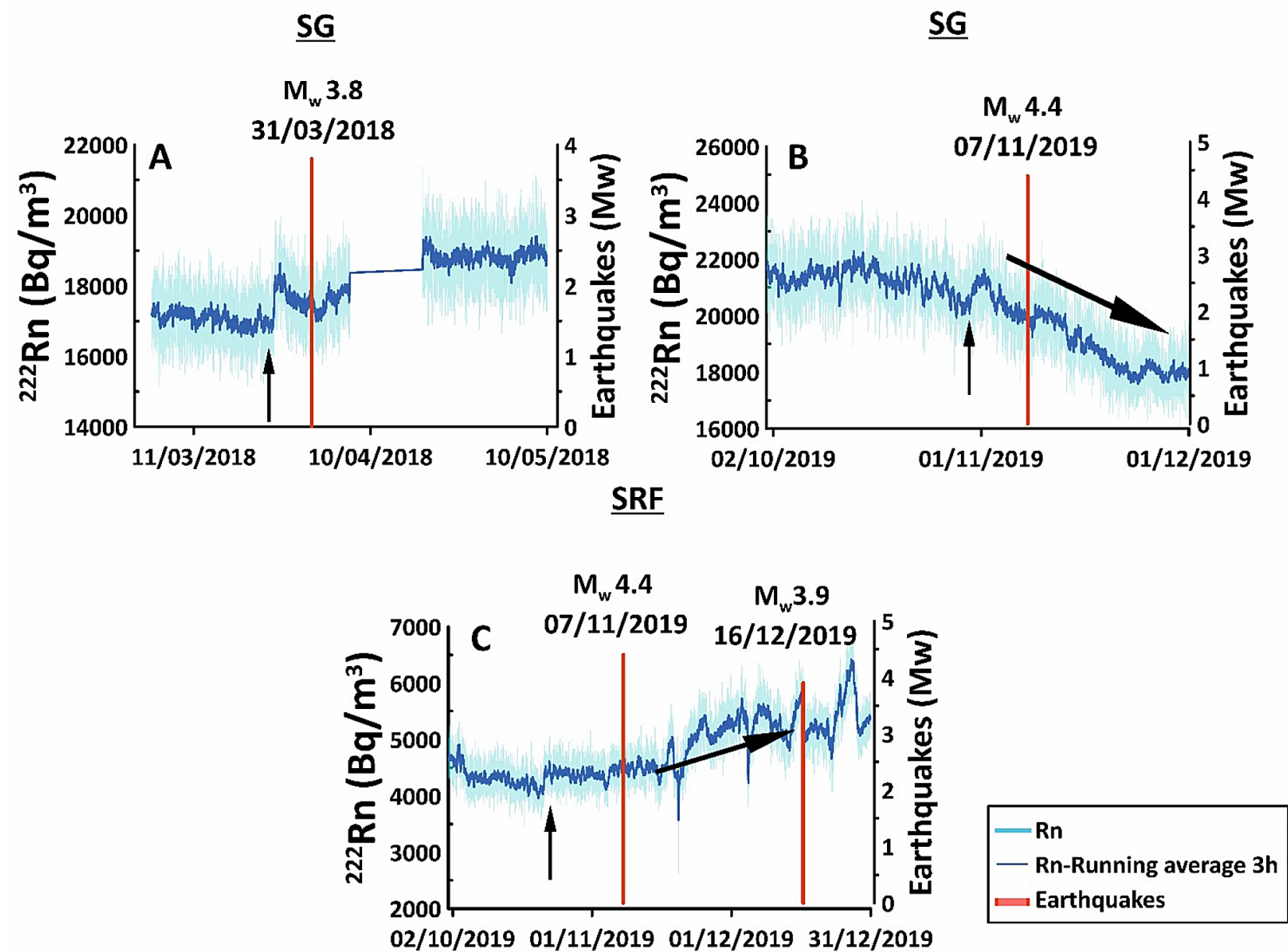

Fig. 7 Time series of $\mathrm{Rn}$ concentrations in relation to seismic activity. The seismic events that produced expected Rn activity responses are shown with red bars. A $M_{w} 3.8$ L'Aquila earthquake occurred on March 31st, 2018, detected at SG; B $M_{w} 4.4$ Balsorano earthquake occurred on 7 November 2019, detected at SG; C $M_{\mathrm{w}}$

the duration of the anomalies until the signals returned to stable background values.

Considering the anomalies recorded on the Rn time series at the two sites, the correlation between the selected events (for which a response was expected) and the hydrogeochemical time series acquired in the SG and SRF areas was investigated. Indeed, the monthly sampling of some selected springs in the two areas made it possible to detect some anomalies in springs with deeper input $[12,14]$. Box-and-whiskers statistical analyses performed on the hydrogeochemical data of these springs revealed anomalous values (outliers) in $\mathrm{Li}, \mathrm{V}, \mathrm{Cr}$ and Cs concentrations in the Raiano spring (Fig. 2A) before the Balsorano earthquake, for which anomalies in Rn content were recorded at both stations (i.e. the SG and SRF in Fig. 7).

The recorded variations and trends identified in the hydrogeochemical time series of the Rn-monitored SG and
3.9 San Leucio del Sannio earthquake occurred on 16 December 2019 and $M_{\mathrm{w}} 4.4$ Balsorano earthquake occurred on 7 November 2019 , both recorded at SRF. The black arrows show the identified anomalies

SRF did not show clear relationships with seismic events. Nevertheless, a potential response could exist that is represented by the behaviour of some elements and ions, such as $\mathrm{Cl}, \mathrm{SO}_{4}$ and $\mathrm{Fe}$, and parameters such as electrical conductivity and temperature at the $\mathrm{SG}$, where limited changes were recorded. Moreover, the sampling frequency of the water chemistry (every month) did not allow comparisons with the $\mathrm{Rn}$ time series (one measurement every $10 \mathrm{~min}$ ). Therefore, the availability of longer time series data is essential for the correct evaluation of the variations in the acquired series.

\section{Conclusions}

The properties of $\mathrm{Rn}$ as an extremely mobile and nonreactive gas makes it an ideal tracer in water with the potential use in the short-term forecast of earthquakes. When used 
in conjunction with other chemical and physical parameters, its prediction significance is greatly enhanced. This study performed continuous monitoring of dissolved Rn in two springs (the SG and the SRF) in central-southern Italy. This monitoring was and remains aimed at identifying potential gas-geochemical precursors to nearby earthquakes. Despite the absence of intermediate-strong seismic events during the monitoring period, some preliminary results can be drawn from the ongoing research:

- The first three years of gas-geochemical monitoring (April 2017 to December 2019) highlighted a good stability of Rn concentrations in two springs fed by regional carbonate aquifers in central-southern Italy.

- Significant $\mathrm{Rn}$ increases recorded before three small seismic events $\left(M_{w}<4\right)$ confirm that the preliminary results achieved are promising and are in line with the international known approaches and results $[10,18,21$, 45]. Indeed, significant $\mathrm{Rn}$ anomalies were found for all monitored seismic events that were expected to influence the $\mathrm{Rn}$ concentration in groundwater based on the strain radius ( $R$ in $\mathrm{km}$ ) of the effective precursory manifestation zone.

- Specifically, the $M_{w} 4.4$ Balsorano earthquake, which occurred on 7 November 2019, produced significant responses in Rn concentrations in both springs as well as hydrogeochemical anomalies before this seismic event in concentrations of $\mathrm{Li}, \mathrm{V}, \mathrm{Cr}$ and $\mathrm{Cs}$ that were recorded at the nearby Raiano spring.

- The hydrogeochemical time series acquired at SG and SRF showed no significant relationship to seismic events. The difference between the sampling frequencies of the gas-geochemical and hydrogeochemical monitoring did not allow comparisons to be made between the recorded Rn anomalies and the geochemical time series.

- On the basis of the above-mentioned results, we are confident that the expansion of the monitoring network through the installation of additional sensors for the measurement of dissolved $\mathrm{Rn}$ in water will allow geoscientists to shed light on the behaviour of this gas in relation to crustal deformation processes, depending on the earthquake's magnitude and epicentral distance.

Acknowledgements Open access funding provided by Università degli Studi di Roma La Sapienza within the CRUI-CARE Agreement. This work was partially funded by Fondazione ANIA (www.fonda zioneania.it) through the HydroQuakes Project involving Fondazione ANIA, Istituto di Geologia Ambientale e Geoingegneria (IGAG-CNR), and Sapienza Università di Roma. We thank Dr Umberto Guidoni (Fondazione ANIA) and his collaborators for granting the permit to publish these results. We are also indebted to Prof Carlo Doglioni
(INGV, Sapienza University of Rome) who conceived, promoted and supported the interdisciplinary researches on hydrogeochemical anomalies in seismic areas of central Italy. We thank also the local drinking water company ACA Pescara and A.S.R. Molise Acque and in particular Walter Di Bartolomeo and his colleagues for their kindness.

Authors' contributions Conceptualization, $\mathrm{MB}, \mathrm{AB}$, and MP; Data curation, MDB, FG, FC, SF, LL; Formal analysis, MDB, FG; Methodology, MDB, FG; Project administration, MP; Supervision, MB, AB, and MP; Validation, $\mathrm{MB}$ and MP; Writing-original draft, MDB and FG; Writingreview \& editing, $M P, M B, A B$; Geological and Hydrogeological framing $M D B, F G, M B, A B, F C, S F, L L, M P$.

Availability of data and materials Not applicable for that section.

\section{Compliance with ethical standards}

Conflict of interest The authors declare that they have no competing interests.

Code availability Office, QGis, Grapher.

Open Access This article is licensed under a Creative Commons Attribution 4.0 International License, which permits use, sharing, adaptation, distribution and reproduction in any medium or format, as long as you give appropriate credit to the original author(s) and the source, provide a link to the Creative Commons licence, and indicate if changes were made. The images or other third party material in this article are included in the article's Creative Commons licence, unless indicated otherwise in a credit line to the material. If material is not included in the article's Creative Commons licence and your intended use is not permitted by statutory regulation or exceeds the permitted use, you will need to obtain permission directly from the copyright holder. To view a copy of this licence, visit http://creativecommons .org/licenses/by/4.0/.

\section{References}

1. Wakita H, Nakamura Y, Notsu K, Noguchi M, Asada T (1980) Radon anomaly: a possible precursor of the 1978 Izu-Oshimakinkai earthquake. Science 207(4433):882-883. https://doi. org/10.1126/science.207.4433.882

2. Toutain JP, Baubron JC (1999) Gas geochemistry and seismotectonics: a review. Tectonophysics 304(1-2):1-27. https://doi. org/10.1016/S0040-1951(98)00295-9

3. Montgomery DR, Manga M (2003) Streamflow and water well responses to earthquakes. Science 300(5628):2047-2049. https ://doi.org/10.1126/science.1082980

4. King CY, Zhang W, Zhang Z (2006) Earthquake-induced groundwater and gas changes. Pure Appl Geophys 163(4):633-645. https://doi.org/10.1007/s00024-006-0049-7

5. Reasenberg PA (1999) Foreshock occurrence before large earthquakes. J Geophys Res Solid Earth 104(B3):4755-4768. https:// doi.org/10.1029/1998JB900089

6. Lucente FP, De Gori P, Margheriti L, Piccinini D, Di Bona M, Chiarabba C, Piana Agostinetti N (2010) Temporal variation of seismic velocity and anisotropy before the 2009 MW 6.3 L'Aquila earthquake, Italy. Geology 38(11):1015-1018. https://doi. org/10.1130/G31463.1

7. Fraser-Smith AC, Bernardi A, McGill PR, Ladd M, Helliwell RA, Villard OG Jr (1990) Low-frequency magnetic field measurements 
near the epicenter of the Ms 7.1 Loma Prieta earthquake. Geophys Res Lett 17(9):1465-1468. https://doi.org/10.1029/GL017 i009p01465

8. Riguzzi F, Crespi M, Devoti R, Doglioni C, Pietrantonio G, Pisani AR (2012) Geodetic strain rate and earthquake size: new clues for seismic hazard studies. Phys Earth Planet Inter 206:67-75. https://doi.org/10.1016/j.pepi.2012.07.005

9. Roeloffs EA (1988) Hydrologic precursors to earthquakes: a review. Pure Appl Geophys 126:177-209. https://doi. org/10.1007/BF00878996

10. King CY, Koizumi N, Kitagawa $Y$ (1995) Hydrogeochemical anomalies and the 1995 Kobe earthquake. Science 269(5220):38-40

11. Skelton $A$, Andrén $M$, Kristmannsdóttir $H$, Stockmann $G$, Mörth CM, Sveinbjörnsdóttir Á, Jónsson S, Sturkell E, Guðrúnardóttir HR, Hjartarson H, Siegmund H, Kockum I (2014) Changes in groundwater chemistry before two consecutive earthquakes in Iceland. Nat Geosci 7(10):752-756. https://doi.org/10.1038/ ngeo2250

12. Barberio MD, Barbieri M, Billi A, Doglioni C, Petitta M (2017) Hydrogeochemical changes before and during the 2016 Amatrice-Norcia seismic sequence (central Italy). Sci Rep 7(1):1-12. https://doi.org/10.1038/s41598-017-11990-8

13. Boschetti T, Barbieri M, Barberio MD, Billi A, Franchini S, Petitta $\mathrm{M}$ (2019) $\mathrm{CO}_{2}$ inflow and elements desorption prior to a seismic sequence, Amatrice-Norcia 2016, Italy. Geochem Geophys Geosyst 20(5):2303-2317. https://doi.org/10.1029/2018GC008117

14. Barbieri M, Boschetti T, Barberio MD, Billi A, Franchini S, lacumin P, Selmo E, Petitta M (2020) Tracing deep fluid source contribution to groundwater in an active seismic area (central Italy): a combined geothermometric and isotopic $(\delta 13 C)$ perspective. J Hydrol 582:124495. https://doi.org/10.1016/j.jhydr ol.2019.124495

15. Martini $\mathrm{C}$ (2016) Signals in water-the deep originated $\mathrm{CO}_{2}$ in the Peschiera-Capone acqueduct in relation to monitoring of seismic activity in central Italy. Acque Sotterranee-Ital J Groundw. https://doi.org/10.7343/as-2016-246

16. Sano $Y$, Takahata N, Kagoshima $T$, Shibata $T$, Onoue $T$, Zhao D (2016) Groundwater helium anomaly reflects strain change during the 2016 Kumamoto earthquake in Southwest Japan. Sci Rep 6:37939. https://doi.org/10.1038/srep37939

17. Buttitta D, Caracausi A, Chiaraluce L, Favara R, Morticelli MG, Sulli A (2020) Continental degassing of helium in an active tectonic setting (northern Italy): the role of seismicity. Sci Rep 10(1):1-13. https://doi.org/10.1038/s41598-019-55678-7

18. Kawabata K, Sato T, Takahashi HA, Tsunomori F, Hosono T, Takahashi M, Kitamura Y (2020) Changes in groundwater radon concentrations caused by the 2016 Kumamoto earthquake. J Hydrol. https://doi.org/10.1016/j.jhydrol.2020.124712

19. Riggio A, Santulin M (2015) Earthquake forecasting: a review of radon as seismic precursor. B Geofis Teor Appl. https://doi. org/10.4430/bgta0148

20. Ching-Chou F, Walia V, Yang TF, Lou-Chuang L, Liu TK, ChengHong C, Arvind K, Shih-Jung L, Tzu-Hua L, Kuo-Liang W (2017) Preseismic anomalies in soil-gas radon associated with $2016 \mathrm{M}$ 6.6 Meinong earthquake, Southern Taiwan. TAO Terr Atmos Ocean Sci 28(5):7. https://doi.org/10.3319/TAO.2017.03.22.01

21. Kuo T, Chen W, Ho C (2018) Anomalous decrease in groundwater radon before $2016 \mathrm{Mw}$ 6.4 Meinong earthquake and its application in Taiwan. Appl Radiat Isot 136:68-72. https://doi. org/10.1016/j.apradiso.2018.02.015

22. Morales-Simfors N, Wyss RA, Bundschuh J (2019) Recent progress in radon-based monitoring as seismic and volcanic precursor: a critical review. Crit Rev Environ Sci Technol 50:979-1012. https://doi.org/10.1080/10643389.2019.1642833
23. King PT, Michel J, Moore WS (1982) Groundwater geochemistry of 228Ra, 226Ra, 222Rn. Geochim Cosmochim Acta 46:11731182. https://doi.org/10.1016/0016-7037(82)90003-5

24. Pinault JL, Baubron JC (1997) Signal processing of diurnal and semidiurnal variations in Radon and atmospheric pressure: a new tool for accurate in situ measurement of soil gas velocity, pressure gradient, and tortuosity. J Geophys Res 102:1810118120. https://doi.org/10.1029/97JB00971

25. Tanner $A B$ (1980) Radon migration in the ground: a supplementary review. Nat Radiat Environ III 1:5-56

26. Adinolfi Falcone R, Carucci V, Falgiani A, Manetta M, Parisse B, Petitta M, Rusi S, Spizzico M, Tallini M (2012) Changes on groundwater flow and hydrochemistry of the Gran Sasso carbonate aquifer after 2009 L'Aquila earthquake. Ital J Geosci 131(3):459-474. https://doi.org/10.3301/IJG.2011.34

27. Holub RF, Brady BT (1981) The effect of stress on radon emanation from rock. J Geophys Res Solid Earth 86(B3):1776-1784. https://doi.org/10.1029/JB086iB03p01776

28. Hauksson E (1981) Radon content of groundwater as an earthquake precursor: evaluation of worldwide data and physical basis. J Geophys Res Solid Earth 86(B10):9397-9410. https:// doi.org/10.1029/JB086iB10p09397

29. Igarashi G, Saeki S, Takahata N, Sumikawa K, Tasaka S, Sasaki Y, Takahashi M, Sano Y (1995) Ground-water radon anomaly before the Kobe earthquake in Japan. Science 269:60-61. https://doi. org/10.1126/science.269.5220.60

30. Barberio MD, Gori F, Barbieri M, Billi A, Devoti R, Doglioni C, Petitta M, Riguzzi F, Rusi S (2018) Diurnal and semidiurnal cyclicity of Radon (222Rn) in groundwater, Giardino spring, central Apennines, Italy. Water 10(9):1276. https://doi.org/10.3390/ w10091276

31. Petitta M, Mastrorillo L, Preziosi E, Banzato F, Barberio MD, Billi A, Cambi C, De Luca G, Di Carlo G, Di Curzio D, Di Salvo C, Nanni T, Palpacelli S, Rusi S, Saroli M, Tallini M, Tazioli A, Valigi D, Vivalda $P_{,}$ Doglioni C (2018) Water-table and discharge changes associated with the 2016-2017 seismic sequence in central Italy: hydrogeological data and a conceptual model for fractured carbonate aquifers. Hydrogeol J 26(4):1009-1026. https://doi.org/10.1007/ s10040-017-1717-7

32. Doglioni C, Harabaglia P, Martinelli G, Mongelli F, Zito G (1996) A geodynamic model of the Southern Apennines accretionary prism. Terra Nova 8(6):540-547. https://doi. org/10.1111/j.1365-3121.1996.tb00783.x

33. Scrocca D (2010) Southern Apennines: structural setting and tectonic evolution. J Virtual Explor 36:13

34. Curzi M, Aldega L, Bernasconi SM, Berra F, Billi A, Boschi C, Franchini S, Van der Lelij R, Viola G, Carminati E (2020) Architecture and evolution of an extensionally-inverted thrust (Mt. Tancia Thrust, Central Apennines): Geological, structural, geochemical, and K-Ar geochronological constraints. J Struct Geol. https:// doi.org/10.1016/j.jsg.2020.104059

35. Cavinato GP, Celles PD (1999) Extensional basins in the tectonically bimodal central Apennines fold-thrust belt, Italy: response to corner flow above a subducting slab in retrograde motion. Geology 27(10):955-958. https://doi.org/10.1130/00917613(1999)027\%3c0955:EBITTB\%3e2.3.CO;2

36. Galadini F, Galli P (2000) Active tectonics in the central Apennines (Italy) - input data for seismic hazard assessment. Nat Hazards 22(3):225-268. https://doi.org/10.1023/A:1008149531 980

37. Galli P, Galadini F, Pantosti D (2008) Twenty years of paleoseismology in Italy. Earth-Sci Rev 88(1-2):89-117. https://doi. org/10.1016/j.earscirev.2008.01.001

38. Trippetta F, Petricca P, Billi A, Collettini C, Cuffaro M, Lombardi AM, Scrocca D, Ventura G, Morgante A, Doglioni C (2019) From mapped faults to fault-length earthquake magnitude (FLEM): a 
test on Italy with methodological implications. Solid Earth. https ://doi.org/10.5194/se-10-1555-2019

39. Allocca V, Manna F, De Vita P (2014) Estimating annual groundwater recharge coefficient for karst aquifers of the southern Apennines (Italy). Hydrol Earth Syst Sci 18(2):803-817. https:// doi.org/10.5194/hess-18-803-2014

40. Conese M, Nanni T, Peila C, Rusi S, Salvati R (2001) Idrogeologia della Montagna del Morrone (Appennino abruzzese): Dati preliminari. Mem Soc Geol Ital 56:181-196

41. Fiorillo F, Pagnozzi M (2015) Recharge processes of Matese karst massif (southern Italy). Environ Earth Sci 74(12):7557-7570. https://doi.org/10.1007/s12665-015-4678-y

42. Civita M (1969) Valutazione analitica delle riserve in acque sotterranee alimentanti alcune tra le principali sorgenti del massiccio del Matese (Italia meridionale). Boll Soc Nat Napoli 78:133-163

43. Petrella E, Celico F (2009) Heterogeneous aquitard properties in sedimentary successions in the Apennine chain: case studies in southern Italy. Hydrol Process 23(23):3365-3371. https://doi. org/10.1002/hyp.7441

44. Esposito A, Galvani A, Sepe V, Atzor S, Brandi G, Cubellis E, De Martino P, Dolce M, Massucci A, Obrizzo F, Riguzzi F, Tammaro $\mathrm{U}$, Pietrantonio G (2020) Concurrent deformation processes in the Matese massif area (Central-Southern Apennines, Italy). Tectonophysics 774:228234. https://doi.org/10.1016/j.tecto .2019 .228234

45. Igarashi G, Wakita H (1990) Groundwater radon anomalies associated with earthquakes. Tectonophysics 180(2-4):237-254. https://doi.org/10.1016/0040-1951(90)90311-U
46. Heinicke J, Koch U, Martinelli G (1995) $\mathrm{CO}_{2}$ and radon measurements in the Vogtland Area (Germany) - a contribution to earthquake prediction research. Geophys Res Lett 22(7):771-774. https://doi.org/10.1029/94GL03074

47. Chaudhuri $H$, Barman $C$, lyengar AS, Ghose $D$, Sen $P$, Sinha $B$ (2013) Network of seismo-geochemical monitoring observatories for earthquake prediction research in India. Acta Geophys 61(4):1000-1025. https://doi.org/10.2478/s11600-013-0134-0

48. Hauksson E, Goddard JG (1981) Radon earthquake precursor studies in Iceland. J Geophys Res Solid Earth 86(B8):7037-7054. https://doi.org/10.1029/JB086iB08p07037

49. Dobrovolsky IP, Zubkov SI, Miachkin VI (1979) Estimation of the size of earthquake preparation zones. Pure Appl Geophys 117(5):1025-1044. https://doi.org/10.1007/BF00876083

50. Silva HG, Bezzeghoud M, Oliveira MM, Reis AH, Rosa RN (2013) A simple statistical procedure for the analysis of radon anomalies associated with seismic activity. Ann Geophys 56(1):0106. https ://doi.org/10.4401/ag-5570

51. Pinter N, Grenerczy G, Weber J, Medak D, Stein S (2006) The Adria microplate: GPS geodesy, tectonics and hazards. Springer, Berlin

Publisher's Note Springer Nature remains neutral with regard to jurisdictional claims in published maps and institutional affiliations. 